\title{
A COMPARISON OF THE EFFECT OF DIFFERENT INSTRUMENT KINEMATICS ON APICAL DEBRIS EXTRUSION
}

\author{
Ashraf Samir Mahmoud Refai*
}

\begin{abstract}
Objective: The aim of this study was to evaluate the effect of instrument kinematics on the apical extrusion of debris. Materials \& Methods: Fourteen single rooted mandibular premolars with single single canals were used in this study. The teeth were divided into to two groups: Group 1: WaveOne Group (Reciprocation Group) and Group 2: OneCurve group (Continuous Rotation Group). The teeth were then accessed and the buccal cusp was reduced so that the external tooth length of all the teeth was $18 \mathrm{~mm}$. The teeth were secured using composite resin in pre-weighed Eppendorf tubes and instrumentation of the canals using the different instruments was done. The teeth were then removed from the tubes and the tubes were incubated for 15 days and then weighed to evaluate the amount of extruded debris. Results: No significant difference in the amount apical extruded debris was found between the WaveOne Gold and the OneCurve instrument. Conclusion: The kinematics of the instruments used in this study did not affect the amount of extruded debris.
\end{abstract}

Keywords: Waveone, Onecurve, extrusion of debris, Kinematics

\section{INTRODUCTION}

Post-operative pain is very common after routine endodontic treatment, this pain can be very distressing for both patients and dentists alike. One of the main causes of post-operative is the extrusion of debris, microorganisms and irrigant solution into the apical tissues. This can result in an inflammatory response which is responsible for the pain ${ }^{(1,2)}$. Historically, instrumentation was done using hand driven files but since the introduction of automated NiTi instruments in the early 1990's, automated instrumentation has become the gold standard. With the first generation of rotary NiTi instruments, it became evident that the amount of apically extruded debris produced by rotary NiTi instruments was significantly lower than that produced by hand instrumentation using the step back technique ${ }^{(3)}$. The main reason for this is because most rotary instruments are used in a crown down technique. Since their introduction, many different rotary instruments with different designs have been introduced into the endodontic market all of them extrude debris apically with varying degrees ${ }^{(4-5)}$.

One of the main drawbacks of using rotary NiTi instruments is the increased possibility of instrument separation. Altering instrument kinematics for instance, reciprocation motion, can reduce the possibility of instrument separation ${ }^{(6)}$. Up until 2002, the idea of using different instrument kinematics had not been suggested, until Malentica and Lalli, published a paper outlining the use of NiTi files with a reciprocating motion ${ }^{(7)}$. Furthermore, in 2008, Yared published a novel article in which he described canal preparation using only one NiTi rotary instrument in a reciprocating motion ${ }^{(8)}$. This article ushered in the age of single file instrumentation. In 2011, the first single file reciprocating instrument was introduced to the endodontic market. At about the same time, companies started manufacturing single file continuous rotation systems.

The first article comparing the effect of rotary vs reciprocating movement of NiTi instruments on

\footnotetext{
* Associate Professor of Endodontics Al-Azhar Univesity (Boys Branch)
} 
debris extrusion was published by De-Deus et al. $2010^{(9)}$. In this study they found that instrument kinematics didn't have a significant effect on the amount of extruded debris. Since then, research has been done comparing both continuous rotation and reciprocation with contradictory results $(10,11,12,13,14,15)$. Some research has also been done comparing continuous rotation and reciprocating single file systems ${ }^{(16)}$. More recently, improvement in instrument metallurgy, has produced new 'modified' NiTi instrument which are designed to be more flexible and more resistance to separation ${ }^{(17)}$. The WaveOne Gold (Dentslpy) and the OneCurve (Micromega) instruments are both examples of reciprocating and continuous rotation instruments manufactured out of modified NiTi alloy, respectively. This research was aimed to evaluate the effect of different instrument kinematics on apical debris extrusion when using modified NiTi instruments, with a null hypothesis between the two groups.

\section{MATERIALS AND METHODS}

A total of 25 single rooted mature mandibular premolar teeth were collected from the surgery department outpatient clinic at Al-Azhar University (Boys Branch) for use in this study. The teeth were extracted from patient with ages ranging from 1825 years for orthodontic or periodontal reasons. The Teeth were cleaned, disinfected, radiographed and examined under $8 \mathrm{x}$ magnification to eliminate teeth with more than one canal, defects and abnormalities i.e. calcified canals, vertical fractures and abnormal canal curvatures. The canal curvatures were measured using the Schneider technique ${ }^{(18)}$ and any teeth with a canal curvature greater than $10^{\circ}$ was eliminated from the study and replaced with another one. The teeth were stored in normal saline till the time of testing. Access to the pulp space was done using a size \#1 round bur mounted in a highspeed contra angled hand piece with coolant (NSK, Nakanishi Inc.; Tochigi, Japan) followed by access cavity refinement using an Endo $\mathrm{Z}$ bur. The tooth length was standardized by flattening the buccal cusp tip, using a taper diamond stone, until the external tooth length was equal to $18 \mathrm{~mm}$.

Following access cavity preparation, patency of the canal was established using a size \#10 followed by a size \#15 (Dentsply Maillefer, Ballaigues, Switzerland). The working length was standardized at $17 \mathrm{~mm}, 1 \mathrm{~mm}$ shorter than the external tooth length. Any tooth in which a size \#15 file would not bind was also eliminated from the study and replaced with another one. A total of 11 teeth were eliminated from this study due to the abovementioned exclusion criteria. The remaining 14 teeth were then divided into two groups: Group 1 $(n=7)$, Teeth in this group were instrumented using the primary WaveOne Gold instrument (Dentsply Maillefer, Ballaigues, Switzerland) (Size \#25 \& 7\% Taper) in a reciprocating motion and Group $2(n=7)$, While in this group they were instrumented using the OneCurve instrument (Micro-Mega, France) (Size \#26 \& 6\% Taper) in a continuous rotation motion. All teeth were instrumented using the above-mentioned files mounted in a X-Smart Plus Endodontic Motor (Dentsply Maillefer, Ballaigues, Switzerland). For the WaveOne Gold instrument the motor was set to the pre-assigned settings, while for the OneCurve instrument the speed and torque settings were set at $300 \mathrm{RPM}$ and $2.5 \mathrm{~N} / \mathrm{cm}$ per the manufacturers instructions. Prior to instrumentation, the canals were filled brim full with with $5.25 \%$ $\mathrm{NaOCl}$ (Egyptian company for house-hold bleach, Cairo, Egypt) and instrumentation commenced. Instrumentation was done in three phases coronal, middle and apical instrumentation, between each phase the instrument was removed cleaned and the canal was irrigated with $3 \mathrm{ml}$ of $5.25 \% \mathrm{NaOCl}$ using an endodontic syringe with a 30 -gauge side vented needle, followed by patency with a size \#15 file. Once the instrument reached the full working length the instrument was retracted and final irrigation was done using $3 \mathrm{ml}$ of $\mathrm{NaOCl}$ followed by final patency using a size \#15 file. 
In this study, the extruded debris was assessed using the method described by Myers \& Montgomery ${ }^{(19)}$. In this method Eppendorf tubes were used to gather any extruded debris. Each empty Eppendorf tube was weighed prior to instrumentation using a microbalance with a precision of $0.00001 \mathrm{gm}$ (AT21 comparator; Mettler Toledo, Greifensee-Zurich, Switzerland). The teeth were then placed inside a separate modified Eppendorf tube cap alongside a 27-gauge irrigating needle and sealed within the cap with composite resin. The modified cap was then attached to the specific previously weighed Eppendorf tube and the whole apparatus (Eppendorf tube with attached tooth and needle) was tightly fit to the opening of a dark glass vial, to prevent contact with the apparatus during instrumentation and to prevent bias. Following instrumentation, the tooth was lightly removed from the Eppendorf tube and the external surface of the root was irrigated with $1 \mathrm{ml}$ of distilled water which was collect within the Eppendorf tube. The Eppendorf tube was removed from the glass vial, sealed and incubated for 15 days at $37^{\circ} \mathrm{C}$ to allow for complete desiccation. Following incubation, the tubes were then weighed again. The tubes were weighed three times and an average reading was taken. The post-instrumentation weight was subtracted from the pre-instrumentation weight to obtain the weight of the extruded debris.

\section{RESULTS}

The data was recorded, tabulated and statistically analyzed using the Mann-Whitney $\mathrm{U}$ test. The significance level was set at $\mathrm{P} \leq 0.05$. Statistical analysis was performed using the IBM SPSS Statistics Version 20 for Windows (IBM Corporation, NY,USA). The WaveOne Gold (Group 1) showed the highest mean value of debris extrusion $0.00037 \mathrm{gm} \pm 0.00017$, while the OneCurve (Group 2) showed the lowest mean value of debris extrusion $0.00029 \mathrm{gm} \pm 0.00023$. Statistical analysis showed no significant difference between the two instrument groups $P$-Value $\leq 0.05$ (Table $1 \&$ Fig 1$)$.
TABLE (1) Mean, standard deviation (SD) values and results of the Mann-Whitney U test for the comparison of extruded debris weights between the two instruments.

\begin{tabular}{|c|c|c|c|c|}
\hline \multicolumn{2}{|c|}{ WaveOne Gold } & \multicolumn{2}{c|}{ OneCurve } & \multirow{2}{*}{$P$-value } \\
\cline { 1 - 3 } Mean & SD & Mean & SD & \\
\hline 0.00037 & 0.00017 & 0.00029 & 0.00023 & 0.277 \\
\hline
\end{tabular}

*: Significant at $p \leq 0.05$

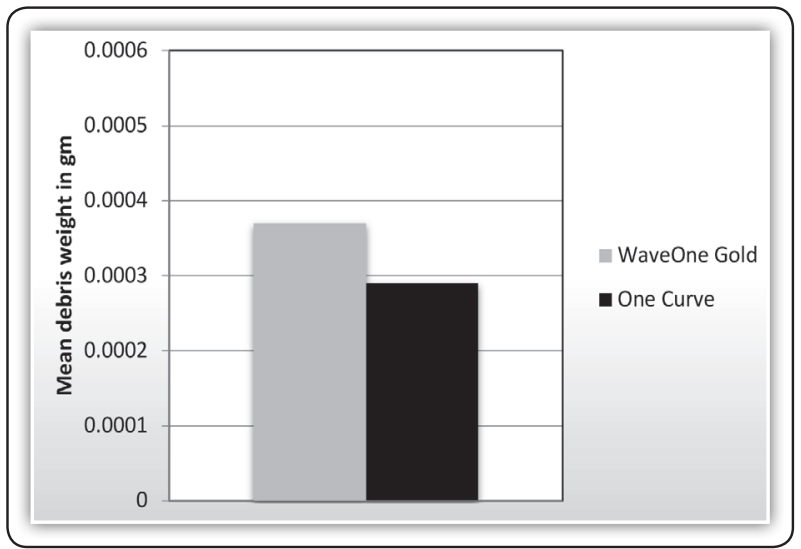

FIG (1) A bar chart comparing the mean weight of extruded debris for the instrument

\section{DISCUSSION}

The use of automation during instrumentation of root canals is a mainstay in endodontic treatment. It is clear from previous research that instrument design and material of manufacture (Modified NiTi alloy) may affect the performance of these instruments with regards to canal shaping, instrument fatigue and apical extrusion of debris ${ }^{(14,18,20)}$ extrusion of debris during instrumentation is one of the main causes of postoperative pain ${ }^{(2)}$. The aim of this study was to evaluate the amount of apically extruded debris when using two types of modified NiTi instruments with different kinematics (patterns of motion). These instruments were selected based on the kinematics with which the instrument is used, the WaveOne Gold, representing reciprocation 
motion and the OneCurve, representing continuous rotation motion. The null hypothesis was that the amount of apically extruded debris would be the same for both instruments. In this study, the null hypothesis was accepted.

The total number of teeth used in this study was 14 divided into two groups $(n=7)$, this sample size was based on a power analysis done on the research by Bürklein and Schäfer ${ }^{(21)}$ in which the minimum sample size was estimated to be 14 teeth with $95 \%$ confidence level. In this study single rooted teeth with a curvature between $0^{\circ}-10^{\circ}$ were preferred over multirooted teeth simplify standardization, it has been previously concluded that canal curvatures have no effect on the amount of apically extruded debris ${ }^{(22)}$ Irrigation was done using $5.25 \% \mathrm{NaOCl}$ and a 30-guage needle to closely represent a clinical setting. The experimental model used in this study to measure the amount of extruded debris was based on a study done by Myers \& Montgomery ${ }^{(20)}$ this model has been used previously in similar $\operatorname{research}^{(13,14)}$.

In this study, the analysis of the data revealed that the WaveOne Gold instrument produced a higher mean value of apically extruded debris (0.00037 gm \pm 0.00017$)$ compared to the OneCurve $(0.00029 \mathrm{gm} \pm 0.00023)$. Although, there was a difference, the difference was not significant. These results are in disagreement with recent research comparing continuous rotation instruments and reciprocating instruments $(11,12,13,14,17)$. On the other hand these results are in agreement with other research done in this field ${ }^{(15,16)}$. Although a large amount of research has shown that reciprocating motion produces more apical debris, there is still a substantial amount of research which indicates that instruments used in reciprocation are comparative to ones used in continuous rotation, with regards to apical debris extrusion. Bürklein and Schäfer ${ }^{(22)}$ explained that reciprocating instrument act as "Screw Conveyer" that pushes debris into the apex. Although, this is true both instruments showed no significant difference in apically extruded debris. This can be due to multiple reasons, first of all, none of the above-mentioned research evaluated the OneCurve instrument. Secondly, the OneCurve instrument has sharp flutes and wide helical angles between the flutes which may account of a higher cutting efficiency hence more debris. Finally, most of the above-mentioned research compared single file reciprocating instruments like the WaveOne Gold and other multiple file continuous rotation systems (no single file continuous rotation systems). Multiple file systems incrementally increase the size of the canal so the amount of cut dentin per file is less and more frequent irrigation in between files may account for less debris extrusion for multiple file continuous rotation systems.

On the other hand, Both the WaveOne Gold instrument and the OneCurve instrument are modified NiTi instruments and this gives these instruments more flexibility which is beneficial in managing curved canals, but this may also affect the cutting efficiency of these instrument compared to similar instruments made out of more rigid alloys. With less cutting efficiency, in advertently more pressure is applied to the instrument and this may result in more apical extruded debris. The conundrum is that this is true for both kinematics. It is more likely, that the apical debris extrusion is a factor of instrument design and not of the material of manufacture. Further research may need to be done to evaluate multiple file systems and single file continuous rotation systems with regards to apical debris extrusion. Furthermore, care needs to be taken when translating these results to the clinical setting, complex anatomy and management of the working length also factor into the amount of apical extruded debris.

\section{CONCLUSIONS}

Within the parameters of this study the following conclusion was drawn. The kinematics of the instruments used in this study did not affect the amount of extruded debris. 


\section{REFERENCES}

1. Gotler M, Bar-Gil B, Ashkenazi M. Postoperative Pain after Root Canal Treatment: A Prospective Cohort Study. Int J Dent. 2012; 2012: 310467

2. Gambarini G, Al-Sudani D, Di Carlo S, Pompa G, Pacifici A, Pacifici L, Testarelli L. Incidence and Intensivity of Postoperative Pain and Periapical Inflammation after Endodontic Treatment with Two Different Instrumentation Techniques. European Journal of Inflammation. Eur. J. Inflamm.2012:10:99-103

3. Beeson T, Hartwell G, Thornton J, Gunsolley G. Comparison of debris extruded apically in straight canals: conventional filing versus profile .04 taper series 29. J Endod. 1998;24:18-22.

4. Koçak M, Çiçek E, Koçak S, Sağlam B, Furuncuoğlu F. Comparison of protaper Next and hyflex instruments on apical debris extrusion in curved canals. Int Endod J. 2016;49(10):996-1000

5. Hinrichs R, Walker W, Schindler W. A comparison of amounts of apically extruded debris using handpiecedriven nickel-titanium instruments systems. J Endod. 1998;24:102-6.

6. Ferraz C, Gomes N, Gomes B, Zaia A, Teixeira F, SouzaFilho F. Apical extrusion of debris and irrigants using two hand and three engine-driven instrumentation techniques. Int Endod J. 2001;34:354-8.

7. da Frota M F, Espir C G, Berbert F L et al. Comparison of cyclic fatigue and torsional resistance in reciprocating single-file systems and continuous rotary instrumentation systems. J Oral Sci. 2014;56(04):269-275

8. Augusto Malentacca, Fabio Lalli. Use of nichel-titanium files with reciprocating movement, Giornale Italiano di Endodonzia 2002;16:79-48

9. Yared G. Canal preparation using only one ni-ti rotary instrument: preliminary observations. Int Endod J. 2008;41:339-44

10. De-Deus G, Brandão M, Barino B, Di Giorgi K, Fidel R, Luna A. Assessment of apically extruded debris produced by the single-file protaper $\mathrm{f} 2$ technique under reciprocating movement. Oral Surg Oral Med Oral Pathol Oral Radiol Endod. 2010;110:390-4

11. Bhat SA. Evaluation of Apical Extruded Debris with Different File Systems. Int J Res Health. 2016;2(3):45-47
12. Bordagaray T, Steinfort K, Martin Pendola M, Monardes $\mathrm{H} \&$ Abarca J. Evaluation of apical debris extrusion and patency in continuous and reciprocating rotary endodontic systems. J Oral Res. 2019; 8(4):325-330.

13. Sachin R, Zinnie N, Jinet J, Srinidhi Sr, Shyam B. Comparison of the Amount of Extrusion Using Two Rotary Files and Reciprocating File System. J. appl. dent.2019;5 (4):45-51

14. Eshagh AS, Sediqe E, Mersad S. Apical Debris Extrusion with Conventional Rotary and Reciprocating Instruments. Iran. Endod. J. 2020;15(1): 38-43

15. Koçak S, Koçak M, Sağlam B, Türker S, Sağsen B, Er Ö. Apical extrusion of debris using self-adjusting file, reciprocating single-file, and 2 rotary instrumentation systems. J Endod. 2013;39:1278-80

16. Ozsu D, Karatas E, Arslan H, Topcu M. Quantitative evaluation of apically extruded debris during root canal instrumentation with protaper Universal, protaper next, waveone, and self-adjusting file systems. Eur J Dent. 2014; 8: $504-8$

17. Tüfenkçi P,Yilmaz K, Adigüzel M. Effects of the endodontic access cavity on apical debris extrusion during root canal preparation using different single-file systems. Restor Dent Endod.2020;45(3)

18. Bhat A, Raikumar B. A comparative evaluation of cyclic fatigue resistance for different endodontic NiTi rotary files: An in-vitro study. J Oral Biol Craniofac Res. 2019 Apr-Jun; 9(2): 119-121

19. Schneider S. A comparison of canal preparations in straight and curved root canals. Oral Surg Oral Med Oral Pathol. 1971;32:271-5.

20. Myers G, Montgomery S. A comparison of weights of debris extruded apically by conventional filing and canal master techniques. J Endod. 1991; 17:275-9.

21. Srivastava S, Alghadouni MA, Alotheem HS. Current Strategies in Metallurgical Advances of Rotary NiTi Instruments: A Review. J Dent Health Oral Disord Ther 9(3): 00333

22. Bürklein S, Schäfer E. Apically extruded debris with reciprocating single-file and full-sequence rotary instrumentation systems. J Endod. 2012;38:850-2

23. Elmsallati E, Wadachi R, Suda H. Extrusion of debris after use of rotary nickel-titanium files with different pitch: A pilot study. Aust Endod J. 2009;35:65-9.;24:102-6 
